\title{
Passing the baton — to whom?
}

\author{
Aldo A. Rossini \\ Division of Diabetes, University of Massachusetts Medical School, Worcester, Massachusetts, USA.
}

\begin{abstract}
Scientific discovery occasionally occurs as a sudden and dramatic leap ahead but more often proceeds at a subtler and steadier pace. Each small step forward may escape public notice but is ultimately vital to the journey's success. Indeed, such gradual advancement represents the collective contributions of many workers in the field, some new to the journey. While the notion of combined effort and multiple contributors is honorable, it poses an inherent danger. In our society, unproven, unorthodox, or unnoticed researchers may not receive the funding or support needed to make their contributions. Furthermore, even if they have the potential to make a leap, a hostile environment may preclude their doing so. This article concentrates on the looming crisis in diabetes research, but the principles pertain to all fields of clinical and biomedical science.
\end{abstract}

\section{Progress in diabetology: an overview}

Although it may seem that advancements in the diabetes field occur independently of each other, establishing cures for metabolic diseases is a complex, intertwined, global effort. Over the past four decades, there have been a significant number of advancements, including the ability to monitor blood sugars, use of insulin pumps, measurement of hemoglobin A1c to provide a timeintegrated glycemic record, and the advent of specific treatment modalities such as laser treatment for diabetic retinopathy and use of angiotensin-converting enzyme inhibitors for hypertension and protection of the renal microvasculature. Other breakthroughs include islet cell transplantation and a plethora of new oral hypoglycemics and insulin preparations that allow fine tuning of glycemic control. Although islet cell allografting is widely considered to be safe, the gap between reality and hope for this treatment is still wide. Lastly, perhaps the most important advancement in the field of diabetes research has been the empowerment of patients to serve as caregivers in the treatment of their disease. Treatments must be made available that offer reasonable risk/benefit ratios, that is, the ability to mitigate the disease without engendering negative effects on the health or lifespan of our patients. The problem of equipoise, achieving therapeutic efficacy without ceding safety, must be at the forefront of any clinician's mind when treating a patient with diabetes.

Although these discoveries and innovations have greatly assisted the study and treatment of this disease, they may all be considered downstream advancements, meaning their benefit is not exerted until the patient is already in the grip of diabetes. It is imperative that we pursue an upstream approach that seeks to identify the causes of and develop prevention methods for the disease.

\section{Funding science: a historical context}

If we are to further our understanding of diabetes and develop an upstream approach, good science and data collection are needed. I suggest that we will only succeed by actively recruiting young, enthusiastic investigators to this effort; this opinion is based on historical reflection. A major impetus to the progress of science in the United States was provided by the Soviet Union's successful launch of Sputnik 1 in 1957. In the immediate aftermath of this event, President Eisenhower mobilized funding for science and research. An even greater commitment was made by President

Conflict of interest: The author has declared that no conflict of interest exists. Citation for this article: J. Clin. Invest. 117:285-288 (2007). doi:10.1172/JCI31089.
Kennedy a few years later. To be sure, there were several motives linking the Soviet Union's achievement with the US government's largesse. First, and perhaps least laudable, was the intensely competitive, even paranoid, nature of East-West relations during the Cold War. Second, the US economy entered a period of unprecedented growth. Scientific investment was a predictable extension. Government funding of research befitted our status as the postwar superpower. Third, the post-World War II period was characterized by a national love affair with all things aerospace; popular culture reflects this as the heyday of science fiction.

Biomedical research, however, also flourished in this environment. Between 1956 and 1980, over 40 new medical schools were established (1). Scientific societies began to proliferate. In the 1960s and 1970s organizations such as the American Society for Clinical Investigation (ASCI), the American Federation for Clinical Research (AFCR; now known as the American Federation for Medical Research), and the Association of American Physicians (AAP) blossomed and became the vehicles by which "young Turks" could be recognized for their contributions. Their success was readily embraced by older investigators. Simply put, the elder statesmen supported the newcomers. Young people were given special consideration for grants and presentations, and their growth and development benefited the entire scientific community.

\section{Investing in the next generation}

The pyramid in Figure 1A outlines the path of the typical researcher in 2003. For each person successfully negotiating the rungs of the educational ladder and becoming a funded investigator, hundreds follow other paths. The odds are against anyone getting from the bottom of this pyramid to the top. In part, this is because few of our high school graduates choose to further their educations in science. As demonstrated in Figure 1B, even among those earning bachelor's degrees in science and engineering, relatively few continue on to seek advanced degrees or careers in science (2). It is likely that much of the attrition is due to the rigors and economic hardships posed by a career in academia. Returning to Figure 1A, we can see how few of those holding advanced degrees will compete successfully for federal funding. As it stands, the path toward a successful scientific career is one of high resistance. Seeking quicker, more certain prospects for financial remuneration, just over half of recipients of science and engineering bachelor's degrees opt not to continue their education and immediately seek work outside the academic realm. Only $1.25 \%$ of high school graduates eventually receive a $\mathrm{PhD}$ degree, a clear indicator of the difficulty of this task. 


\section{A 2003 US education statistics}

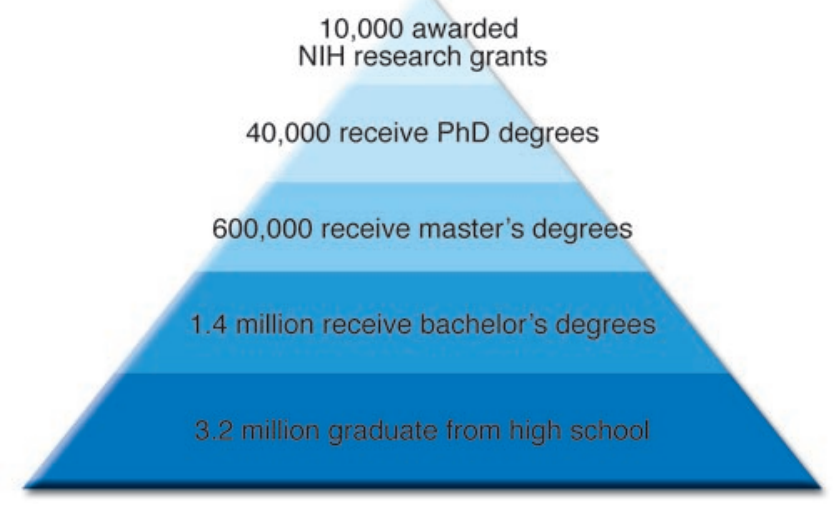

B

Academic paths of baccalaureate recipients in science and engineering

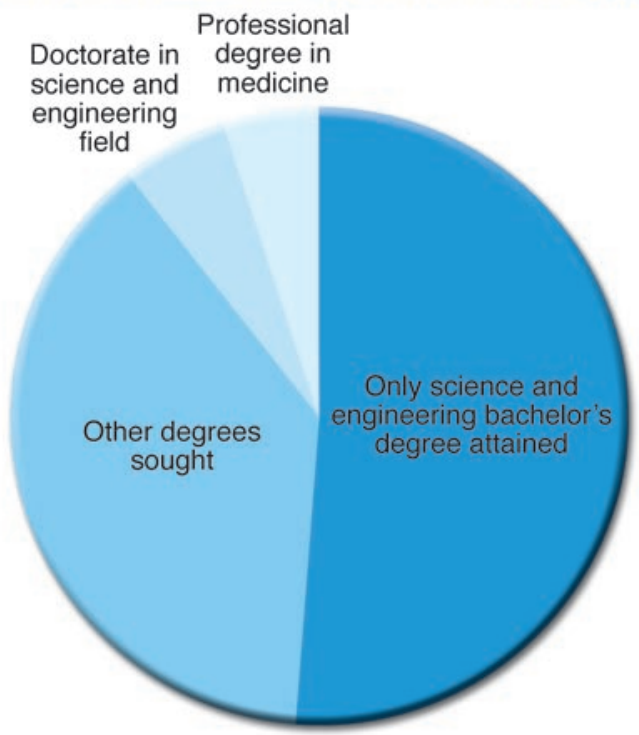

Figure 1

The road not taken. (A) The federal research funding pyramid. Only a minuscule fraction of US high school graduates are destined to become recipients of federal research funding. (B) Distribution of baccalaureate recipients in science and engineering by ultimate educational degree attained (2).

It may be argued that the challenges inherent to becoming an academic scientist are helpful in narrowing the number of researchers to only the best and most dedicated. Is this really the case? Early in their careers, scientists have the broadest knowledge base and the greatest versatility they will ever have. They approach research differently from scientists who have been focused on one particular goal for many years. They are the stem cells of the scientific community: pluripotent. To winnow out this group drastically is to lessen our odds for scientific advancement.

The importance of youth to science can be appreciated by examining the ages of Nobel laureates at the time of their sentinel accomplishments. As shown in Figure 2, over half of these celebrated discoveries were made by investigators under 40 years of age (3). A number of explanations can be posited for the phenomenon of disproportionate achievement by the young: fewer distractions, more focused research, and a youthful willingness to take risks coupled with a relative unwillingness to accept prevailing dogma.

\section{Funding}

For the past four decades the main source of research funding has been the NIH, the leading sponsor of research within its own system as well as in other organizations and schools of higher learning, specifically the 125 medical schools in the United States. A disturbing trend becomes apparent as one examines data showing the average age of NIH grant recipients. At the present time, the average $\mathrm{PhD}$ receiving his or her first $\mathrm{R} 01$ grant is 42 years old, while for an MD the age is almost 45 . Equally troubling is the fact that the mean age has steadily risen since 1992, when $30 \%$ of grant recipients were under the age of 30 . Today this has shrunk to $18 \%$. A reciprocal increase is seen in the percentage of grants going to recipients over 50 years of age, as shown in Figure 3 (4). Money accrues disproportionately to those most experienced in obtaining it. The new investigator, less skilled in grant writing, is kept at a competitive disadvantage. Our scientific enterprise cannot sustain this obliviousness.

\section{The looming extinction of diabetes researchers}

There are a number of reasons for the thinning ranks of clinical scientists, as exemplified by the near extinction of pediatric diabetes researchers. Foremost among these are lack of funding, lack of mentorship, educational debt, and clinical demands.

The first problem, lack of funding, stems from the fact that many clinical scientists have difficulty competing for grant support against technology- and molecular science-driven grant applicants. Lack of mentorship may stem from the same problem. Because many clinical endocrinologists face the same funding problem as their junior colleagues, they are at a competitive disadvantage when seeking grants and must find alternative sources of funding. Competition under such circumstances can lead to negativity among scientists.

The inability to find funding for projects is compounded by the frustration of the young investigator struggling to pay off medical school loans. The educational debt accrued by most new investigators is staggering. An average researcher, on leaving a private medical school, owes $\$ 150,000$. Those finishing public school are not much better off, with an average debt of $\$ 115,000$ (5). Debts may grow during clinical residency training and serve as a disincentive to a young person who might otherwise wish to fulfill a passion for research. Lack of opportunity for funding causes many to seek a path of less resistance, one offering a greater chance of steady income.

Lastly, the clinical demands upon new investigators can seriously drain their time, detracting from research. To remain secure in an academic environment, a clinician is expected to generate his or her salary through clinical productivity. These demands are growing even as alternative sources of funding become eroded. Less and less time is allowed for scholarly pursuits. Fund streams previously flowing toward the academic physician are either channeled elsewhere or simply evaporating.

\section{Challenges in 2007 and beyond}

Much has been said and written about the disconcerting possibility that the United States may lose its preeminent position as the world's leader in science and technology. In addressing this concern, the government and the public have emphasized the need to 


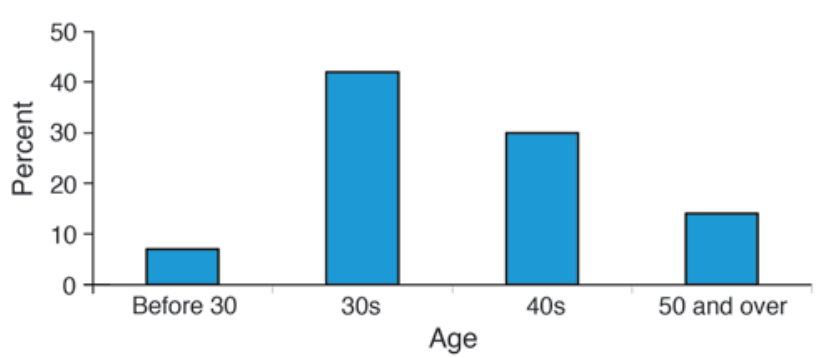

Figure 2

Distribution of Nobel laureates according to age at the time of their key scientific achievements (3). Values are approximate.

strengthen secondary education. Such an initiative, while invaluable, is only part of the answer. Here are a few additional suggestions.

More money for research. It is obvious we need more funding for research. One of the strategies now being touted in the scientific community is to gear funding toward focused research (a "diseaseof-the-month" attitude). It is tempting to funnel more money into a programmatic effort against a specific disease (recall the Nixon administration's "War on Cancer"), but history shows us that major scientific and technologic advances rarely issue from such an approach. It is through more generalized and fundamental research that we are more likely to chance upon scientific breakthroughs. Consider the recent discovery of RNA interference and the development of siRNA technology. This advance, of seemingly boundless scientific and clinical potential, was made possible by support of basic research in the biology of the helminth C. elegans (6). The application of this finding to treatment of diseases has been recently addressed $(7,8)$.

Educate the public. While most people are bombarded by advertisements and commercial messages, they are deprived of legitimate information about science and health. Our hard-pressed scientific and academic institutions have failed to inform the general public in a meaningful and eye-catching way. As clinical scientists we must play a more active role in keeping people informed and prepared to separate the wheat of science from the chaff of marketing. Raising public awareness about health and science might well stimulate interest in supporting or working in these areas. In this country, a grass roots push for science may ultimately translate into a shift in federal budget priorities toward further appropriations for research. This will not happen until we learn how to use the media to advance our cause.

Find creative ways to draw youth to science. It is the responsibility of all scientists to ensure that the flow of bright young minds into investigative careers continues uninterrupted. Young scientists must experience the excitement of science and the thrill of discovery. We also may need to adjust the general public's attitude toward the typical researcher. Scientists dedicating their lives to the betterment of society should be valued as much as athletes and entertainers. This may be accomplished by appealing to adolescents through outreach efforts and summer lab programs for both high school students and teachers.

More support from politicians, business people, organizations, and philanthropists. Support must be forthcoming from a variety of sources. Politicians must continue to provide and protect the funding necessary to ensure that the next generation of scientists will be properly endowed with the resources they need. The funding spigot must not be opened and closed with abandon. Consider that it takes over 30 years to develop a scientist equipped to make an impact on society. It is imperative that they have the infrastructure, mentorship, tools for scientific development, and the finances to support their fledgling scientific career. In order to accomplish this goal, everyone must be involved. Politicians must keep themselves well informed about science. Heads of business must comprehend that developing a workforce of young scientists is crucial to the future viability of our commerce. Research funding is a wise investment of private as well as public funds. We as scientists must raise our profiles in our communities, learn how to lobby our representatives, and gain access to industrial leaders.

Create an environment conducive to fruitful research. At my own institution, the University of Massachusetts, I recently witnessed a compelling example of how a fertile environment permits a young researcher's skills to bear fruit. Such an environment demands a strong infrastructure. Integral to this effort is acknowledgement of the principle that development of a researcher is dependent on interactive basic research, clinical research, and core supports. At UMass, molecular biologists interface with clinical scientists, cell biologists, and others to create a rich milieu for growth and development. A new program bridging clinical and basic science has been instituted using seed money to provide the funds for pilot and feasibility projects between these cultures. A second trial program has been initiated in which young investigators will be supported financially. Five-year salary support for two clinical scientists will be awarded, as will three years of salary support for two PhD scientists engaged in clinically related research. Startup funds will be provided for each investigator. Such sponsorship will ensure sufficient uninterrupted and undistracted time for research. Initially, these projects will be supported by institutional monies. How can this level of support be sustained? Fundraising efforts can generate a pool large enough to subsidize completely an endowed chair for a single young scientist, or partial endowments for several. A legacy program will be established to this end. Clinical scientists will be expected to devote $15 \%-20 \%$ of their time to clinical care, bridging their missions as scientists and clinicians.

These challenges represent the viewpoint of only one scientist, but it will be important to tap the imagination of the entire scientific community. Together, we can find exciting new ways of ensuring that tomorrow's investigators prevail today. It is up to us to ensure the continuation of our work and to pave the road for our successors. We must remember that in 2007 and beyond it takes a scientific village to grow a scientist, and we all need to contribute to this goal.

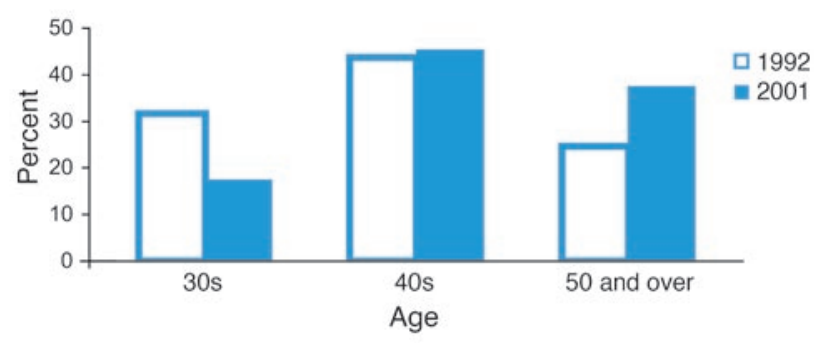

Figure 3

Age distribution of NIH grant recipients. Data from the years 1992 and 2001 are compared (4). A decline in funding for investigators in their 30 s is explained by a reciprocal rise in funding for those aged 50 and above. 


\section{Acknowledgments}

The author would like to thank Katie Warren for her help in organizing data and images. He would also like to thank David Clive for his critical input.

1. Mullan, F. 2000. The case for more U.S. medical students. N. Engl. J. Med. 343:213-217.

2. National Science Foundation, Division of Science Resources Statistics. 2006. What do people do after earning an S\&E bachelor's degree? http://www.nsf. gov/statistics/infbrief/nsf06324.

3. Jones, B. F. 2005. Age and great invention. National Bureau of Economic Research working paper no. 11359. http://www.nber.org/papers/

Address correspondence to: Aldo A. Rossini, Division of Diabetes, University of Massachusetts Medical School, 373 Plantation Street, Suite 218, Worcester, Massachusetts 01605, USA. Phone: (508) 856-3800; Fax: (508) 856-4093; E-mail: aldo.rossini@umassmed.edu.

w11359.

4. Committee on Bridges to Independence, National Research Council (US). 2005. Bridges to independence: fostering the independence of new investigators in biomedi cal research. National Academies Press. Washington, DC, USA. 172 pp.

5. Association of American Medical Colleges. 2006 Medical school graduation questionnaire. http:// www.aamc.org/data/gq
6. Fire, A., et al. 1998. Potent and specific genetic interference by double-stranded RNA in Caenorhabditis elegans. Nature. 391:806-811.

7. Soutscheck, J., et al. 2004. Therapeutic silencing of an endogenous gene by systemic administration of modified siRNAs. Nature. 432:173-178.

8. Bernards, R. 2006. Exploring the uses of RNAi - gene knockdown and the Nobel Prize. N. Engl. J. Med. 355: 2391-2393. 